\title{
Two Agrobacterium tumefaciens CheW Proteins Are Incorporated into One Chemosensory Pathway with Different Efficiencies
}

\author{
Zhiwei Huang, Qingxuan Zhou, Pan Sun, Jing Yang, and Minliang Guo ${ }^{+}$ \\ College of Bioscience and Biotechnology, Yangzhou University, Yangzhou City, Jiangsu 225009, P R China
}

Accepted 24 November 2017.

\begin{abstract}
Agrobacterium tumefaciens is the agent that causes crown gall tumor disease on more than 140 species of dicotyledonous plants. Chemotaxis of $A$. tumefaciens toward the wound sites of the host plant is the first step to recognize the host. CheW is a coupling protein that bridges the histidine kinase CheA and the chemoreceptors to form the chemotaxis core signaling complex and plays a crucial role in the assembly and function of the large chemosensory array. Unlike all previously reported chemotaxis systems, A. tumefaciens has only one major che operon but two cheW homologs (atu2075 as che $W_{1}$ and atu2617 as che $W_{2}$ ) on unlinked loci. The in-frame deletion of either cheW gene significantly affects $A$. tumefaciens chemotaxis but does not abolish the chemotaxis, unless both $\operatorname{ch} W$ genes were deleted. The effect of $c h e W_{2}$ deletion on the chemotaxis is more severe than that of $c h e W_{1}$ deletion. Either $\mathrm{CheW}$ can interact with CheA and couple it to the cell poles. The promoter activity of che $W_{2}$ is always higher than that of $c h e W_{1}$ under all of the tested conditions. When two cheW genes were adjusted to the same expression level by using the identical promoter, the difference between the effects of two CheW proteins on the chemotaxis still existed. Therefore, we envision that both the different molecular ratio of two $\mathrm{CheW}$ proteins in cell and the different affinities of two CheW proteins with CheA and chemoreceptors result in the efficiency difference of two $\mathrm{CheW}$ proteins in functioning in the large chemosensory array.
\end{abstract}

Chemotaxis allows bacterial cells to modulate their swimming patterns in response to chemoeffectors and keeps them moving forward to an optimal environment, especially under adverse conditions (Dogra et al. 2012; Martin et al. 2001; Sourjik and Wingreen 2012). It not only provides a competitive advantage for motile bacteria to survive in harsh environment but also plays a key role in many biological processes such as the invasion of many bacterial pathogens into their hosts (Erhardt 2016; Falke and Piasta 2014; Sourjik and Wingreen 2012), development of bacterial biofilm (Alexandre 2015; He and Bauer 2014; Mangwani et al. 2016; Merritt et al. 2007), chemoattraction of bacteria toward

${ }^{\dagger}$ Corresponding author: M. Guo; E-mail: guoml@yzu.edu.cn

Funding: This work was funded jointly by the National Natural Science Foundation of China (Grant Number 30870054, 31170073) and the Funding Plan for the High-level Talents with Oversea Education to Work in China from Ministry of Human Resources and Social Security of China.

*The $\boldsymbol{e}$-Xtra logo stands for "electronic extra" and indicates that four supplementary figures and two supplementary tables are published online.

(C) 2018 The American Phytopathological Society biodegradable pollutants (Adadevoh et al. 2016; Krell et al. 2013; Kudryasheva and Tarasova 2015; Mangwani et al. 2016; Montaño et al. 2013), and establishment of symbiotic association of bacteria with plants (Scharf et al. 2016).

Most environmental sensing in prokaryotes is performed by a two-component system, which typically consists of a central histidine kinase with a sensor domain and a phosphorylatable response regulator. The chemotaxis signaling transduction system is a special case of this two-component system. In the chemotaxis model bacterium Escherichia coli, the chemotaxis system comprises various chemoreceptors and six core components: CheA, CheW, CheY, CheB, CheZ, and CheR. In this system, the central histidine kinase CheA utilizes transmembrane chemoreceptors (usually called methyl-accepting chemotaxis proteins [MCP]) as sensors to sense the extracellular signal molecules (Bi and Lai 2015; Salah Ud-Din and Roujeinikova 2017) and the signal transduction from MCP sensor to the histidine kinase CheA requires a coupling protein, $\mathrm{CheW}$, which couples CheA to the cytoplasmic part of the chemoreceptor to form a ternary signaling complex (also called a core complex) (Nishiyama et al. 2014). Hundreds of core complexes join together to form the large chemosensory array in a hexagon pattern (Falke and Piasta 2014). As a monodomain protein, CheW plays a crucial role in the assembly and function of this signaling complex (Griswold and Dahlquist 2002; Zhao and Parkinson 2006a,b). In response to the increase of repellent concentration or the reduction of attractant concentration, MCP activates CheA autophosphorylation. Phosphorylated CheA subsequently transfers its phosphoryl groups to two response regulator proteins, $\mathrm{CheB}$ and $\mathrm{CheY}$. The phosphorylated CheY diffuses from the ternary signaling complex to the flagellar motor and changes the rotational direction of flagella from counterclockwise (CCW) to clockwise $(\mathrm{CW})$ by binding to the switch component of the motor. $\mathrm{CCW}$ rotation is the default motor direction that produces forward swimming ("runs"), while CW rotation causes cell tumbling and changes the moving pattern (Parkinson et al. 2015). Hence, the chemotactic behavior of $E$. coli is regulated by the phosphorylation extent of CheY (Dogra et al. 2012). Phosphorylated CheY can dephosphorylate spontaneously and the chemotaxis signal is terminated. This process can be accelerated by the phosphatase CheZ (Hess et al. 1988). Phosphorylated $\mathrm{CheB}$ acts as a methylesterase to remove the methyl groups from the methylated glutamates in the signaling domain of MCP (Springer et al. 1977). Demethylation decreases MCP's ability to activate CheA, resulting in adaptation (Bi and Lai 2015; Salah Ud-Din and Roujeinikova 2017). Chemotactic behaviors and their molecular mechanisms have been intensively studied in the $\gamma$-proteobacterium E. coli. For more details, please see recent reviews (Jones and Armitage 2015; Parkinson et al. 2015; Porter et al. 2011). 
The gram-negative soilborne bacterium Agrobacterium tumefaciens is the causative agent of crown gall tumor disease on a broad range of dicotyledonous plants. A. tumefaciens causes the crown gall tumor disease by transferring a DNA fragment (called T-DNA) from its Ti plasmid to host plant cell and genetically transforming the host (Guo et al. 2009a, 2011; Subramoni et al. 2014). Its ability to mediate the interkingdom DNA transfer and the possibility to replace the oncogenes in the T-DNA with the interest genes have made A. tumefaciens evolve from a phytopathogen to a powerful genetic transformation tool for generating transgenic plants. Therefore, in past decades, A. tumefaciens has attracted the attention of a broad range of scientists, including microbiologists, phytopathologists, plant breeders, and molecular biologists. It has been extensively studied and soon became a model bacterium for the studies of many bioprocesses, which include microbe-plant interaction (McCullen and Binns 2006; Pitzschke 2013), horizontal gene transfer (Bourras et al. 2015; Matveeva and Lutova 2014; Nester 2015), type IV secretion system transport (Chandran 2013; Guo et al. 2007b; Low et al. 2014), and quorum sensing (Lang and Faure 2014; Subramoni et al. 2014). However, only a few studies on A. tumefaciens are related to the chemotaxis signaling mechanism, although chemotaxis is very important for $A$. tumefaciens to recognize the host and seek the invading site in bulk soil. A. tumefaciens is a highly motile bacterium and has a highly sensitive chemotaxis system. It can sense and be attracted toward many attractants such as sugars, amino acids, opines, and phenolic compounds that are released by host plants (Ashby et al. 1987, 1988; Kim and Farrand 1998; Loake et al. 1988). A. tumefaciens commonly lives in the rhizosphere (Escobar and Dandekar 2003) and the invasion of A. tumefaciens into host plant begins with its chemotaxis toward the wound site of the host (Ashby et al. 1987; Hawes and Smith 1989; Hawes et al. 1988; Parke et al. 1987) but the chemotaxis signaling transduction pathway in A. tumefaciens remains unclear.

Most plant-associated bacteria, which include species or strains from the genera Azorhizobium, Azospirillum, Bradyrhizobium, Rhizobium, and Sinorhizobium, have multiple chemotaxis systems (Scharf et al. 2016), whereas, with the exception of most $m c p$ and two cheW genes, the A. tumefaciens C58 genome encodes only one complete set of core chemotaxis proteins and all of the core component-encoding genes are organized into one che operon (Goodner et al. 2001; Guo et al. 2017; Wood et al. 2001; Wright et al. 1998). Deletions of orf1,
cheA, cheY1, cheY2, cheB, and cheR in this che operon impaired the chemotaxis of $A$. tumefaciens toward acetosyringone (AS) (Harighi 2008, 2009; Wright et al. 1998). Unlike the che operon in many bacteria, the A. tumefaciens che operon does not have the CheW-encoding gene, and two cheW homologs (atu2075 as che $W_{1}$ and $a t u 2617$ as che $W_{2}$ ) are found at different loci of the circular chromosome (Goodner et al. 2001; Wood et al. 2001). Until now, the roles of these two cheW homologs in chemotaxis have not been identified. In this study, two cheW genes of $A$. tumefaciens were precisely deleted by gene replacement, and their roles in chemotaxis were investigated by a series of experiments. Our results revealed that two CheW proteins coexist in one chemosensory pathway and both CheW proteins are required for the full chemotaxis signaling transduction in A. tumefaciens; however, the effect of che $W_{2}$ on chemotaxis is more severe than that of $c h e W_{l}$.

\section{RESULTS}

Two CheW proteins are very similar in structure.

In the A. tumefaciens genome, two cheW genes are located at different loci on the circular chromosome rather than in the che operon (Goodner et al. 2001; Wood et al. 2001). There is no putative chemotaxis or motility gene adjacent to $c h e W_{1}$ (atu2075). Only one putative MCP-encoding gene (atu2168) is located downstream of che $W_{2}$ (atu2167). Therefore, the bioinformatics analysis of two CheW proteins is useful for us to further verify the annotation of two cheW genes and get more information about the functions of these two putative CheW proteins. According to the prediction in the genome database, the peptide lengths encoded by $c h e W_{1}$ and $c h e W_{2}$ genes are 155 and 159 amino acid residues, respectively. Sequence alignment with the $\mathrm{CheW}$ from $E$. coli showed that $30.66 \%$ of the $\mathrm{CheW}_{1}$ sequence and $32.68 \%$ of the $\mathrm{CheW}_{2}$ sequence are identical with the sequence of $E$. coli $\mathrm{CheW}$ (Fig. 1). The sequence alignment also showed that both $\mathrm{CheW}_{1}$ and $\mathrm{CheW}_{2}$ contain most of the highly conserved residues, which are identified to be involved in the CheW-MCP and CheW-CheA interactions in E. coli CheW (Alexandre and Zhulin 2003; Boukhvalova et al. 2002a,b; Liu and Parkinson 1989, 1991; Piñas et al. 2016). Due to the high similarity of two A. tumefaciens CheW proteins with $E$. coli $\mathrm{CheW}$, the solution structure of $E$. coli CheW (Li et al. 2007) was used as the structure template to model the structures of these two A. tumefaciens CheW proteins. The homology models of two $A$. tumefaciens $\mathrm{CheW}$ proteins manifested

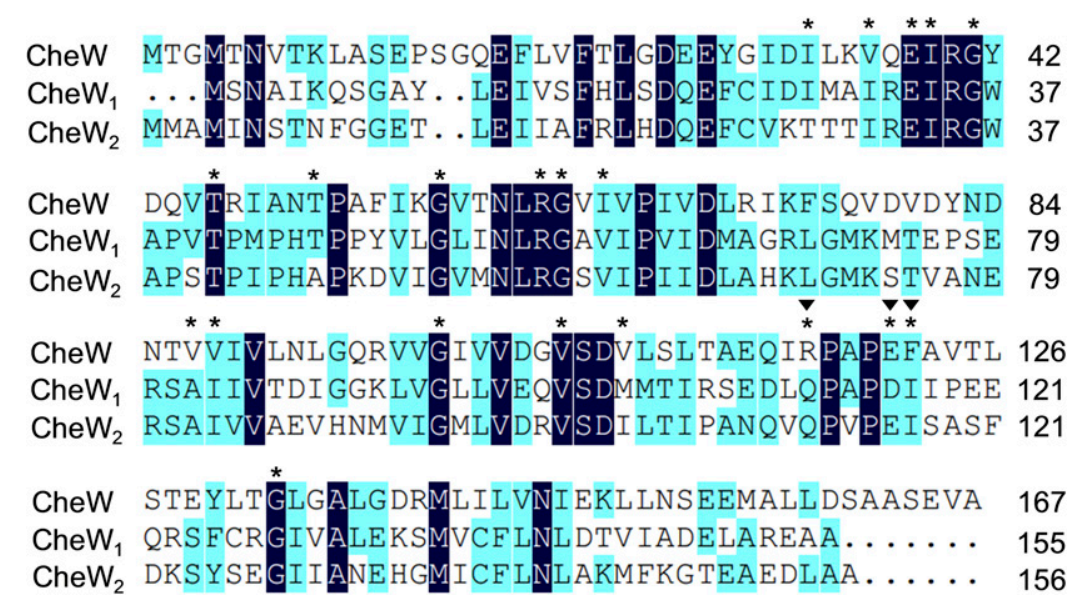

Fig. 1. Sequence alignment of Escherichia coli $\mathrm{CheW}$ and two Agrobacterium tumefaciens $\mathrm{CheW}$ proteins. Numbers on the right indicate the position of amino acid. Sequences of two CheW proteins are from the University of Washington version of the genome data (Wood et al. 2001). Asterisks represent the key residues that are identified to be involved in the CheW-methyl-accepting chemotaxis protein and CheW-CheA interactions in $E$. coli CheW (Alexandre and Zhulin 2003; Boukhvalova et al. 2002a,b; Liu and Parkinson 1989, 1991). Inverted triangles indicate the key residues of $E$. coli CheW for functioning interface 2 interaction between CheW and the P5 domain of CheA (Piñas et al. 2016). 
that the structures of both $A$. tumefaciens CheW proteins are very similar to the structure of $E$. coli $\mathrm{CheW}$, with root-mean-square deviations of backbone atoms less than $0.148 \AA$.

\section{Two cheW genes are expressed simultaneously in the same cell.}

Effective discrimination of two CheW homologous proteins is the prerequisite condition for the study of the expressions of two che $W$ genes. CheW $\mathrm{W}_{1}$ shares $47.17 \%$ sequence identity with $\mathrm{CheW}_{2}$ (Supplementary Fig. S1). If the full-length CheW proteins were used to generate polyclonal antibodies, the antibodies would be likely to cause cross reaction between two CheW proteins and lead to nonspecific results. Therefore, the peptide fragments from the variable sequence regions of these two CheW proteins (142 to 155 amino acid residues of $\mathrm{CheW}_{1}$ and 146 to 159 amino acid residues of $\mathrm{CheW}_{2}$ ) were synthesized and used as antigens to generate the polyclonal rabbit antibodies that could differentiate two $\mathrm{CheW}$ proteins without cross reaction. Two CheW proteins that are heterogeneously produced by $E$. coli BL21 (DE3) can be specifically identified by their corresponding antibodies (Fig. 2), demonstrating that the antibodies are able to discriminate between two CheW proteins and, thus, can be used to test the expressions of two cheW genes. To investigate the expressions and functions of che $W_{1}$ and che $W_{2}$ in A. tumefaciens, two che $W$ genes were precisely deleted by homologous recombination (as described in Materials and Methods). Two single mutants of these two cheW genes were named C58 $\Delta w_{1}$ and $\mathrm{C} 58 \Delta w_{2}$. The double-mutant was named as C58 $\Delta w$. To restore the synthesis of CheW proteins in the mutants, cheW genes with their native promoters (approximately $500 \mathrm{bp}$ upstream of the che $W$ gene) were reintroduced to the corresponding mutants by using plasmids. The complemented mutant strains were named $\mathrm{C} 58 \Delta w_{1}+, \mathrm{C} 58 \Delta w_{2}+$, and C58 $\Delta w+$. The expressions of two che $W$ genes in different strains were verified by Western blot. Immunoblotting results showed that both $\mathrm{CheW}_{1}$ and $\mathrm{CheW}_{2}$ can be detected in the wild type and all of the complemented mutants, demonstrating that both cheW genes can be expressed simultaneously in the same cell and the complemented cheW genes can also be expressed in the mutant strains (Fig. 2). According to the band strengths of two CheW proteins in different strains, the deletion of either cheW gene does not affect the expression of another cheW gene, and both CheW proteins expressed by plasmid show increased levels compared with the wild type. Results also showed that the corresponding CheW proteins in the mutant strains cannot be detected by the Western blot (Fig. 2), confirming that the corresponding cheW genes are deleted.

\section{Two cheW genes have different effects}

\section{on A. tumefaciens chemotaxis.}

A. tumefaciens has only one chemotaxis signaling pathway. CheW bridges CheA to MCP and transfers the signal from different MCP to CheA. What we wanted to know was why A. tumefaciens expresses two CheW proteins for one chemotaxis signaling pathway and whether the two $\mathrm{CheW}$ proteins have different functions. To answer these questions, we characterized the chemotaxis behaviors of cheW-deletion mutants. Swimming in swim agar plate and attraction toward plant leaf disc were used to evaluate the effects of cheW deletions on $A$. tumefaciens chemotaxis. When A. tumefaciens cells were inoculated on the swim agar plate, the cells utilized the nutrients, thus resulting in a nutrient concentration gradient. Bacterial cells with chemotaxis will steadily move outward along the nutrient gradient, thus growing a big colony. The colony size on the swim agar plate is often used to indicate the chemotaxis behaviors of bacteria to nutrient gradient (Sampedro et al. 2015). Because the A. tumefaciens genome possesses only one CheA-encoding gene and CheA is the key player of chemotaxis signaling transduction, the deletion of the cheA gene will be able to abolish the chemotaxis signaling transduction in A. tumefaciens. Therefore, the cheAdeletion mutant of $A$. tumefaciens can be used as a negative control of chemotaxis. The colony size of the double mutant $\mathrm{C} 58 \Delta w$ is the same as that of the cheA-deletion mutant C58 $\Delta a$ (Fig. 3A and B), demonstrating that the deletion of both cheW genes can fully eliminate the chemotaxis signaling transduction and $A$. tumefaciens does not have any other gene that can partially compensate the functions of two cheW genes. Colonies of both

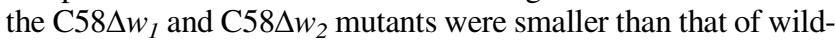
type C58 and the colony of C58 $\Delta w_{2}$ mutant was smaller than that of the $\mathrm{C} 58 \Delta w_{1}$ mutant (Fig. 3A and B), implying that the deletion of either cheW gene is able to weaken the chemotaxis, and that the effect of che $W_{2}$ deletion on the chemotaxis is more severe than that of $c h e W_{1}$ deletion. To verify whether the deletions of che $W$ genes or cheA would affect the growth rate of A. tumefaciens, resulting in the difference of these cheW mutants in colony size, we tested the growth curves of these mutants in AB-sucrose liquid medium. Growth curves showed that the growth rates of these $A$. tumefaciens mutants in AB-sucrose liquid medium were the same as that of the wild-type strain C58 (Supplementary Fig. S2).

Chemotaxis of A. tumefaciens toward attractants can be characterized by the attraction of agrobacterial cells toward a Kalanchoe leaf disc (Su et al. 2006). The leaf disc, which is placed at the center of the swim agar plate, will produce exudates and create an exudate concentration gradient from the plate center to the plate edge. Bacterial cells that can be attracted by the exudates will move toward the plate center along the exudate gradient. The chemotaxis was quantitated by relative migration distance, which was defined as the difference of migration distance between toward and away from the leaf disc (Fig. 3C and D). The results showed that the chemotaxis behaviors of all the A. tumefaciens strains tested with plant wound exudates were similar to those tested with nutrient substances (Fig. 3C and D); in particular, the

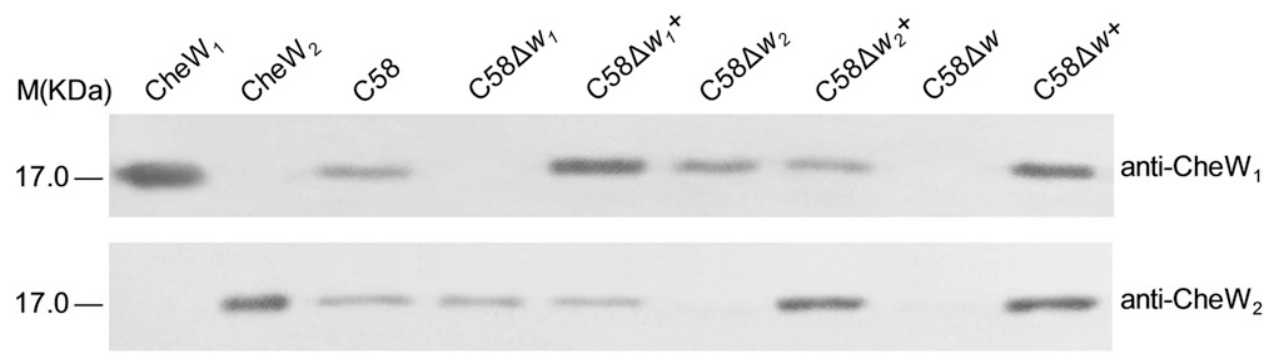

Fig. 2. Western blot analysis of cheW mutants and their complemented strains. Equal amounts of cell crude extracts from different bacterial strains were separated by sodium dodecyl sulfate polyacrylamide gel electrophoresis and then analyzed by immunoblotting. $\mathrm{ChW}_{1}=\mathrm{crude}_{\mathrm{d}}$ extract from the Escherichia coli BL21 (DE3) cells overexpressing the $c h e W_{1}$ gene and $\mathrm{CheW}_{2}=$ crude extract from the $E$. coli BL21 (DE3) cells overexpressing the $c h e W_{2}$ gene. Antibodies used for immunoblotting are listed on the right. Other labels on the top of the lanes represent the Agrobacterium tumefaciens strains where the crude extracts originated. 
relative migration distance of the $\mathrm{C} 58 \Delta w_{2}$ mutant was smaller than that of C58 $5 w_{1}$ mutant. Bacteria use different MCP to sense different chemoeffectors. The chemotactic response of the

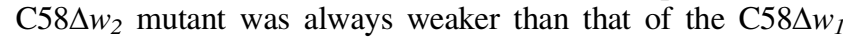
mutant no matter what chemoeffectors they responded to, implying that the effects of the two CheW proteins on the chemotaxis signaling transduction do not depend on the MCP.

\section{Two CheW proteins can transfer the signal} from the same MCP.

To know whether the two CheW proteins can recognize the same MCP and transfer the signal from the same MCP to CheA, we tested the chemotactic responses of $A$. tumefaciens $\mathrm{C} 58$ cheWmutants to a single chemoattractant, AS. AS is a strong chemoattractant to A. tumefaciens (Ashby et al. 1987; Stachel et al. 1985). To test the chemotaxis of bacteria toward a single chemoattractant requires a more sensitive method. Therefore, we used the oldest method for measuring chemotaxis, the capillary assay (Adler 1973; Shaw 1995), to determine the chemotactic responses of $A$. tumefaciens $\mathrm{C} 58$ cheW-deletion mutants to AS. Deficiency of either CheW significantly attenuated the chemotactic response of $A$. tumefaciens to AS and A. tumefaciens required both CheW proteins to completely transfer the chemotaxis signal (Fig. 4). These results suggested that two CheW proteins are able to recognize the same MCP and transfer the signal from the same MCP to CheA, although two CheW proteins may transfer the signal with different efficiencies, implying that two CheW proteins are not responsible for recognizing different $\mathrm{MCP}$; instead, both $\mathrm{CheW}$ proteins can transfer the signal from the same MCP and are incorporated into one chemotaxis signaling pathway. Results also showed that the effect of $c h e W_{2}$ deletion on the attraction of agrobacterial cells toward AS is more severe than that of che $W_{l}$ deletion (Fig. 4).

\section{Both $\mathrm{CheW}_{1}$ and $\mathrm{CheW}_{2}$ interact with CheA.}

Most MCP are transmembrane chemoreceptors and located at the cell poles. CheW acts as an adapter protein to tether CheA to different MCP, forming ternary signaling complexes at the cell poles (Nishiyama et al. 2014; Parkinson et al. 2015; Sourjik and Berg 2000). CheW is essential for the assembly of these ternary complexes. Therefore, we wanted to know whether the two CheW proteins had any significant difference in assembling the ternary complex. To visualize the cellular localization of CheA, an egfp-cheA fusion gene expression cassette was

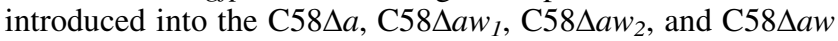
mutant strains by using plasmid. The $e g f p-c h e A$ fusion gene in the plasmid can be expressed by A. tumefaciens into an eGFPCheA fusion protein, in which enhanced green fluorescent protein (eGFP) is fused onto the $\mathrm{N}$ terminus of CheA. It is important to know whether the eGFP-CheA fusion protein still
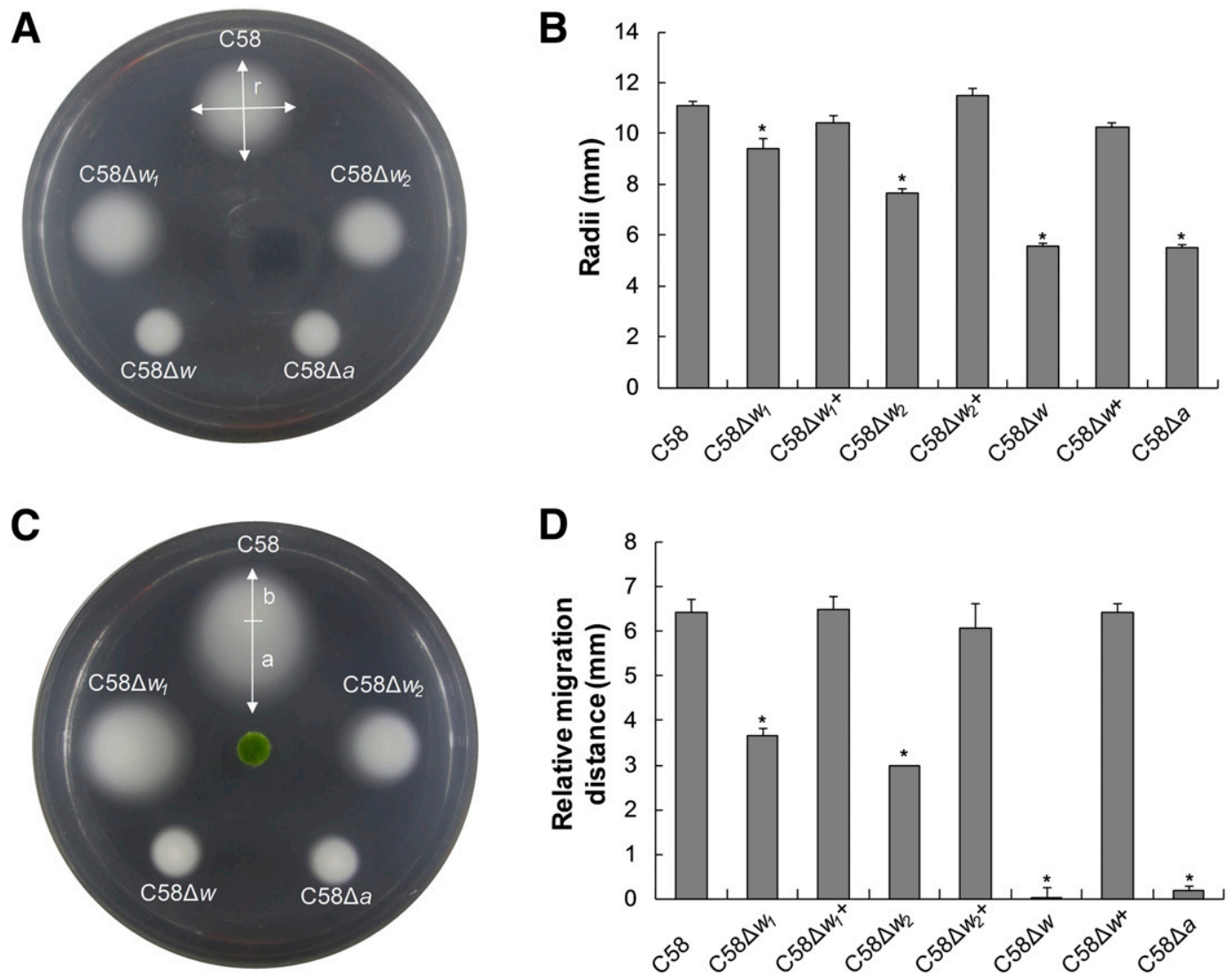

Fig. 3. Chemotactic responses of Agrobacterium tumefaciens C58 cheW-deletion mutants to nutrient substances and plant attractants. Equal amounts of the cells from different $A$. tumefaciens strains that were grown to middle-log phase were inoculated on the swim agar plate. A and $\mathbf{B}$, The radius of the bacterial colony after growing for $48 \mathrm{~h}$ on the swim agar plate was used to quantitate the chemotactic response of $A$. tumefaciens to nutrient substances. For the test of the chemotactic responses of cheW-deletion mutants to plant attractants, a disc of Kalanchoe leaf was placed at the center of the swim agar plate to produce exudate attractants. Each inoculating spot had equal distance from the central leaf disc, so that each strain could be inoculated on the same attractant gradient. $\mathbf{C}$ and $\mathbf{D}$, Chemotaxis toward plant attractants was quantitated by the relative migration distance. Relative migration distance $=$ the distance between the edge toward the leaf disc and inoculating spot - the distance between the edge away from the leaf disc and the inoculating spot. A and $\mathbf{C}$, Typical colonies of different A. tumefaciens strains after growing for $48 \mathrm{~h}$ on the swim agar plate without or with plant leaf disc. B, Colony radii of different $A$. tumefaciens strains after growing for $48 \mathrm{~h}$ on the swim agar plate without leaf disc. D, Relative migration distance of different $A$. tumefaciens strains after growing for $48 \mathrm{~h}$ on the swim agar plate with leaf disc. Data are the means from three plates with standard deviations (B and D). Asterisks $(*)$ represent $P$ values of these strains $<0.01$ compared with the wild type strain C58. Labels on the plate images (A and C) and the horizontal axes (B and D) are the names of the corresponding A. tumefaciens strains. 
has the function of native CheA. Fortunately, the eGFP-CheA fusion protein was able to restore the chemotactic response of the C58 $\Delta a$ mutant (Supplementary Fig. S3). The observation of the fluorescence of these mutant strains showed that the eGFPCheA fusion protein is located at the cell poles in all of the cheA-deletion mutant strains with either or both of the cheW genes but uniformly distributed throughout whole cell in the cheA-deletion mutant with neither of the cheW genes (Fig. 5). These results confirmed that both CheW proteins can couple CheA to MCP and form a stable ternary complex but did not show any discernable difference between two $\mathrm{CheW}$ proteins in coupling CheA to MCP.

An in vitro pull-down experiment was used to further verify the interaction between CheA and CheW. A his-tag was fused onto the $\mathrm{C}$ terminus of CheA to form a CheA-His fusion protein. Another his-tagged fusion protein, SalT-His, which has nothing to do with chemotaxis, was used as a negative control. CheA-His and SalT-His fusion proteins, which were overproduced by $E$. coli, were bound to Ni-IDA resin. The Ni-IDA resins bound with CheA-His or SalT-His were incubated with the crude extract from C58 $\Delta a$ strain to test whether the CheAHis fusion protein can pull down both $\mathrm{CheW}_{1}$ and $\mathrm{CheW}_{2}$ from the crude extract. Both $\mathrm{CheW}_{1}$ and $\mathrm{CheW}_{2}$ were detected in the eluate from the resin bound with CheA-His (Fig. 6, lane 1) but not in the negative control (Fig. 6, lane 2), confirming that both $\mathrm{CheW}_{1}$ and $\mathrm{CheW}_{2}$ can interact with CheA in vitro.

\section{The difference of the effects of $c h e W_{1}$ and $c h e W_{2}$ on chemotaxis arises}

from both the promoter activity and the protein itself.

According to the above results, the deletion of either cheW gene can weaken the chemotaxis behavior and both $c h e W_{1}$ and che $W_{2}$ are required for the full chemotaxis but their effects on chemotaxis are different. Therefore, we wanted to know the cause of the different effects. che $W_{1}$ (atu2075) and che $W_{2}$ (atu2617) are located in different operons and controlled by

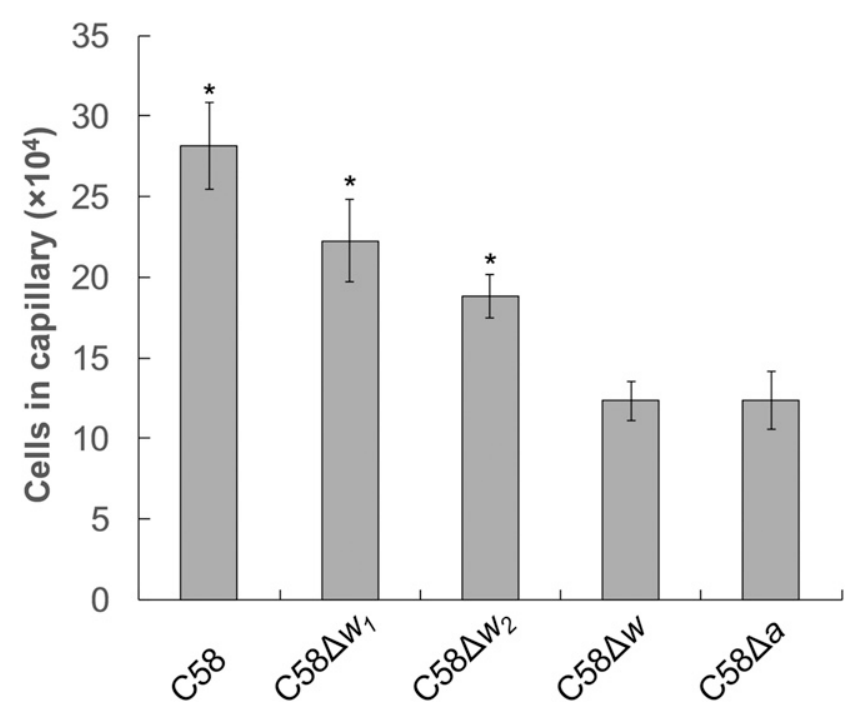

Fig. 4. Chemotactic responses of Agrobacterium tumefaciens C58 cheWdeletion mutants to acetosyringone (AS). Cells of different A. tumefaciens strains, which were grown to middle-log phase, were collected, washed, and resuspended in chemotaxis medium to an optical density at $600 \mathrm{~nm}$ of 0.1 . Capillary tubes containing AS at $10^{-7} \mathrm{~mol} / \mathrm{liter}$ were inserted into the agrobacterial cell suspensions for $1 \mathrm{~h}$ at room temperature $\left(25^{\circ} \mathrm{C}\right)$. Then, the liquid in the capillary tube was transferred, diluted proportionately, and plated in MG/L solid medium for colony count. The results are expressed as the means \pm standard error of the mean from five capillary tubes. Asterisks $\left.{ }^{*}\right)$ in the figure represent $P$ values of these mutants $<0.01$, compared with the chemotaxis-negative strain $(\mathrm{C} 58 \Delta a)$. different promoters. Therefore, the expression levels of $c h e W_{l}$ and $c h e W_{2}$ may be one of the reasons that lead to their different effects on chemotaxis. To determine the promoter activities of two che $W$ genes, a red fluorescent protein (RFP)-encoding gene $(r f p)$ was used as a reporter gene for the in situ substitute for che $W_{1}$ and $c h e W_{2}$. The expression level of the reporter gene $r f p$, which is in situ controlled by the promoter of $c h e W_{1}$ or $c h e W_{2}$, can be quantitated by the RFP fluorescence intensity. Expression of the $r f p$ gene under the in situ control of $c h e W_{1}$ or $c h e W_{2}$ promoter is shown in Figure 7. The fluorescence intensity of the crude extract from the strain, in which the $r f p$ gene is in situ controlled by che $W_{2}$ promoter, is always higher than that of the crude extract from the strain, in which the $r f p$ gene is in situ controlled by che $W_{1}$ promoter, implying that the promoter activity of $c h e W_{2}$ is stronger than that of $c h e W_{l}$. This means that the concentration of $\mathrm{CheW}_{2}$ is always higher than that of $\mathrm{CheW}_{1}$ in $A$. tumefaciens cells, although both the absolute concentrations and the relative ratio of the two $\mathrm{CheW}$ proteins at different growth times may be regulated by the promoters of the two che $W$ genes.

To determine whether the two CheW proteins themselves have different effects on chemotaxis, we compared the effects of the two cheW genes on chemotaxis under the control of an identical promoter. When two cheW genes were controlled by the identical promoter, the concentrations of the two CheW proteins in the cells would be the same. If two cheW genes had different effects on chemotaxis under the control of an identical promoter, the difference of the effects should be ascribed to the CheW proteins themselves. To be able to express two cheW genes in A. tumefaciens cells under the control of an identical promoter, the promoters of $c h e W_{1}$ and $c h e W_{2}$ were exchanged with each other. Generally, a prokaryotic promoter and its regulatory elements are located in the region approximately 500 bp upstream of the gene (Browning and Busby 2016; Minchin and Busby 2009). We constructed four plasmids, which carry four different cheW expression cassettes: $479 \mathrm{bp}$ upstream of the che $W_{1}+$ che $W_{1}$ open reading frame (ORF), $520 \mathrm{bp}$ upstream of the che $W_{2}+$ che $W_{1}$ ORF, 479 bp upstream of the che $W_{1}+$ che $W_{2} \mathrm{ORF}$, and 520 bp upstream of the che $W_{2}+$ $c h e W_{2}$ ORF. The four plasmids were introduced into the C58 $\Delta w$ mutant and the chemotaxis behaviors of these four $\mathrm{C} 58 \Delta w$ strains harboring different plasmids were compared. $c h e W_{1}$ and $c h e W_{2}$ had different effects in restoring the chemotaxis behaviors of the C58 $\Delta w$ strain even if both $c h e W_{1}$ and che $W_{2}$ were under the control of the identical promoter (Fig. 8). To verify whether two CheW proteins have the same expression level under the control of the same promoter, Western blot was used to evaluate the concentrations of two CheW proteins in the cells of different agrobacterial strains. In order to adjust the possible titer difference of two anti-CheW antibodies, two Histagged CheW fusion proteins $\left(\mathrm{CheW}_{1}\right.$-His and $\mathrm{CheW}_{2}$-His $)$, which were expressed under the control of the same promoter, were used as the reference proteins for Western blot. Western blot results confirmed that the actual expression levels of $\mathrm{CheW}_{1}$ and $\mathrm{CheW}_{2}$ are the same when they are expressed under the control of the same promoter (Supplementary Fig. S4). This implies that the expression products of the two cheW genes, $\mathrm{CheW}_{1}$ and $\mathrm{CheW}_{2}$ proteins, have different effects on A. tumefaciens chemotaxis in the same concentration. Results also showed that the efficiencies of the two $\mathrm{CheW}$ proteins to restore the chemotaxis behaviors of the C58 $\Delta w$ strain are dependent on what chemoreceptors they couple CheA to (Fig. 8).

\section{DISCUSSION}

CheW, as an adaptor protein, not only bridges CheA to MCP to form a ternary core signaling complex but also couples the 
kinase control domain of MCP to modulate the kinase activity of CheA (Nishiyama et al. 2014; Parkinson et al. 2015). CheW is essential to chemotaxis (Parkinson and Houts 1982). Although the model organism of chemotaxis, E. coli, has a single coupling protein (CheW), multiple CheW homologs are universal in many bacteria such as Rhodobacter sphaeroides (Martin et al. 2001), Leptospira interrogans (Li et al. 2006), Vibrio cholerae (Butler et al. 2006), and Azospirillum brasilense (Scharf et al. 2016). According to previous studies, multiple cheW homologs include the following four cases. (i) Multiple cheW homologs are located in different chemotaxis operons. Different che $W$ genes are under distinct transcriptional control and induced by different environmental factors. Therefore, different CheW proteins mediate different chemotaxis pathways under different lifestyles and only conditionally affect the chemotactic responses (Martin et al. 2001). (ii) Multiple cheW homologs are located on different loci. Multiple CheW homologs are incorporated into one chemotaxis signaling pathway and any of these $\mathrm{CheW}$ proteins is essential for chemotaxis (Zhang et al. 2012). (iii) Multiple cheW homologs are located on the distinct unlinked loci. Only one of the CheW homologs is essential for chemotaxis. Other CheW homologs are dispensable or functionally redundant for chemotaxis (Butler et al. 2006). (iv) One $\mathrm{CheW}$ with multiple homologs of a related protein $(\mathrm{CheV})$ coexists in the chemotaxis signaling network. CheV consists of a CheW domain fused to a phosphorylatable receiver domain and has $\mathrm{CheW}$ function in the
$\mathrm{N}$ terminus and response-regulator $\mathrm{CheY}$ function in the $\mathrm{C}$ terminus (Lowenthal et al. 2009; Ortega and Zhulin 2016; Pittman et al. 2001). Multiple cheV homologs are located on the distinct unlinked loci (Abedrabbo et al. 2017; Alexander et al. 2010; Pittman et al. 2001; Rosario et al. 1994). CheW and CheV have redundant abilities to interact with MCP and CheA but both $\mathrm{CheW}$ and $\mathrm{CheV}$ are required to modify the formation of a large chemosensory array and, thus, provide flexibility in the large chemosensory array formation (Abedrabbo et al. 2017; Pittman et al. 2001). In our results, both A. tumefaciens cheW genes that are located on two distinct, unlinked loci are required for optimal chemotaxis but neither of them is absolutely necessary for chemotaxis. $\mathrm{CheW}_{1}$ and $\mathrm{CheW}_{2}$ possess largely overlapping or redundant but not identical functions in the chemotactic behavior of A. tumefaciens. This situation of two cheW homologs in A. tumefaciens is different from any of the four previously reported cases, suggesting that the two CheW proteins use a unique mechanism to incorporate into one chemotaxis signaling pathway.

CheW promotes the formation of the MCP-CheW-CheA ternary complex by interacting with both MCP and CheA. The smallest assembly of the ternary core signaling complex contains two MCP trimers-of-dimers, two molecules of CheW, and one CheA homodimer. The minimal core complexes are linked into hexagonal arrays through a unique interface 2 interaction between CheW and the P5 domain of CheA to form large chemosensory arrays at cell poles, producing highly cooperative
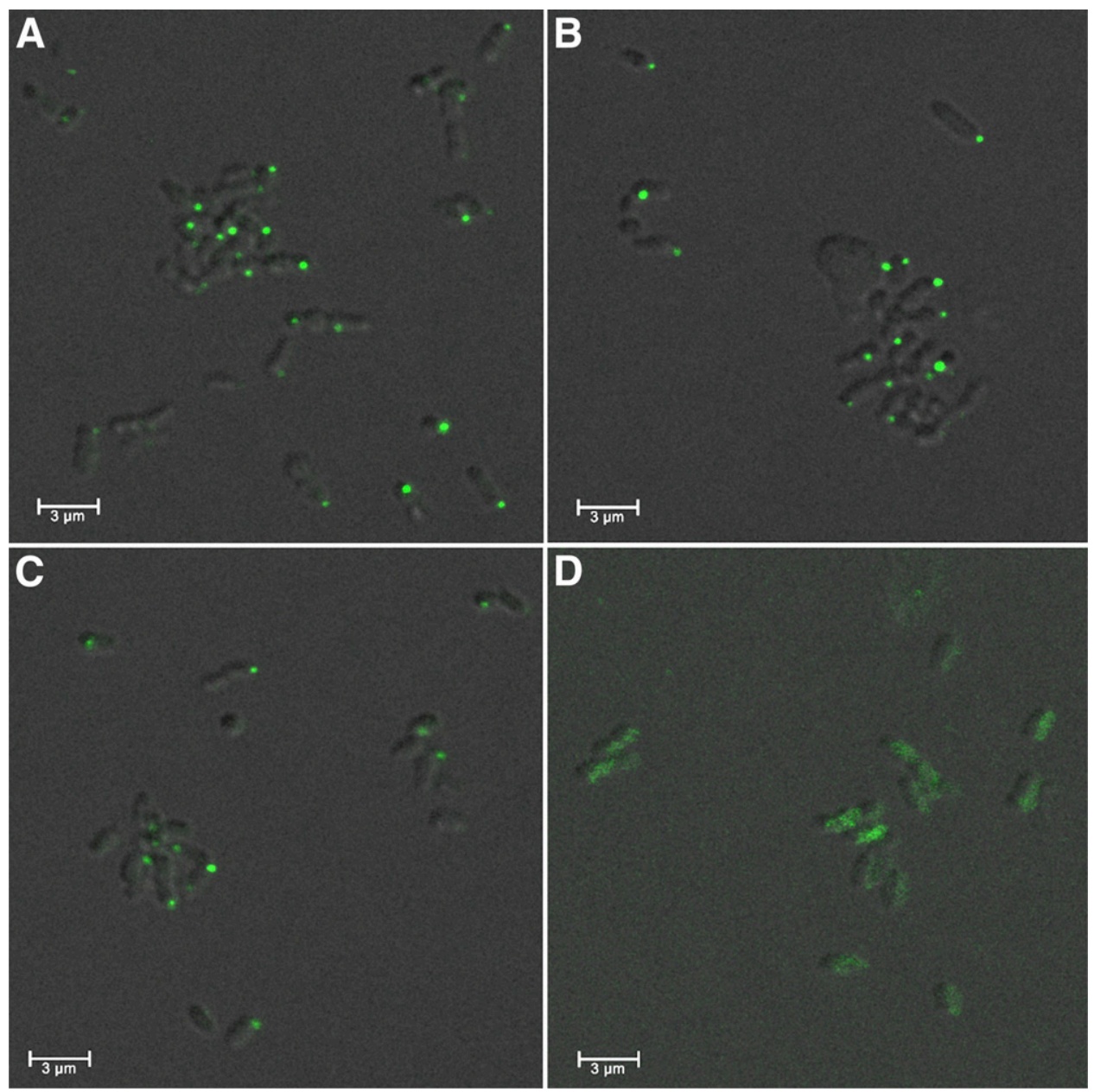

Fig. 5. Cellular localization of CheA in Agrobacterium tumefaciens $\mathrm{C} 58 \mathrm{cheW}$-deletion mutants. Plasmid pUCA-19GA, which carries an egfp-cheA fusion gene expression cassette, was introduced into different A. tumefaciens strains. A. tumefaciens strains harboring this plasmid were grown to middle-log phase. Cells of these strains were observed by using confocal laser-scanning microscopy. A, eGFP-CheA in C58 $\triangle a$ cells. B, eGFP-CheA in C58 $\Delta a w_{1}$ cells. C, eGFP-CheA in

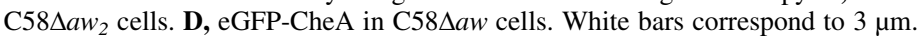


signaling properties (Bi and Lai 2015; Briegel and Jensen 2017; Piñas et al. 2016; Salah Ud-Din and Roujeinikova 2017). The array cooperativity relies on coupling between core complexes through the unique interface 2. Residues R117, E121, and $\mathrm{F} 122$ in the $E$. coli $\mathrm{CheW}$ are the key interface 2 residues (Piñas et al. 2016). However, the residues of two A. tumefaciens CheW proteins in this interface 2 region show very low similarity (Fig. 1), implying that two CheW proteins may have different affinities to interact with CheA in the interface 2 . The difference of the affinities of two CheW proteins to CheA would affect the coupling of CheA and core complex and, thus, the cooperative efficiency of the large chemosensory array. This may explain why two cheW genes still show different abilities to restore the chemotaxis of the cheW double-mutant when their actual expressions are adjusted to the same level by the same promoter. Both the concentration of free CheW and the affinity of CheW to CheA affect the incorporation of CheW into the large chemosensory array, resulting in the variation of the ratio of $\mathrm{CheW}_{1}$ to $\mathrm{CheW}_{2}$ in the large chemosensory array. Finally, the ratio of $\mathrm{CheW}_{1}$ to $\mathrm{CheW}_{2}$ in the large chemosensory array affects the cooperative efficiency of the large chemosensory array in signaling transduction and, thus, affects the chemotactic response. It should be pointed out that excessive CheW can disrupt the chemoreceptor signaling array in E. coli (Cardozo et al. 2010). In our results, the superficial contradiction between the results in Figure 8 and those from Figures 3, 4, and 7 also revealed that the effects of two A. tumefaciens CheW proteins on chemotactic response are dependent on their expression levels. Therefore, the determination of the actual affinities of two CheW proteins to CheA and different MCP will be helpful for us to calculate the normal stoichiometries of CheA, two CheW proteins, and MCP in the large chemosensory array and to quantitate the efficiencies of two CheW proteins in transducing the chemotaxis signal. In addition, the A. tumefaciens mutant with a single MCP will be useful for the understanding of the mechanism of the interaction between MCP and two CheW proteins because A. tumefaciens C58 possesses $20 \mathrm{MCP}$.

\section{MATERIALS AND METHODS}

Plasmids, bacterial strains, and their growth conditions.

Strains of E. coli and A. tumefaciens and the plasmids used in this study are listed in Supplementary Table S1. E. coli strains

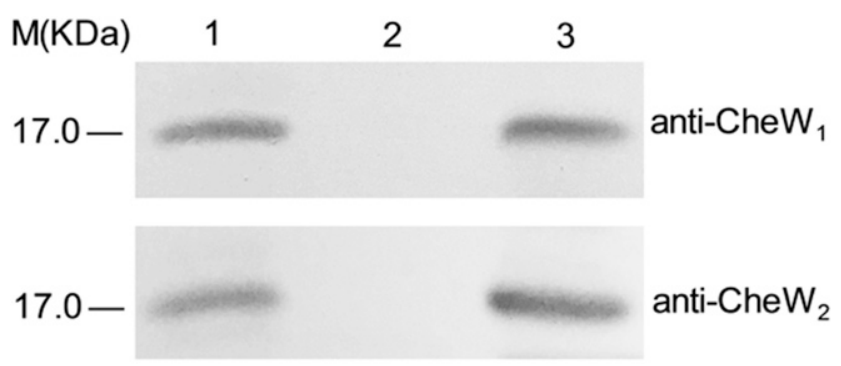

Fig. 6. In vitro analysis of the interactions between CheA and two CheW proteins of Agrobacterium tumefaciens. Interactions between CheA and two CheW proteins were detected by using a His-tag pull-down assay. CheA-His fusion protein overexpressed in Escherichia coli was bound to $\mathrm{Ni}$-IDA resin. Then, the fusion protein-bound resins were incubated with the crude extract of $\mathrm{C} 58 \Delta a$ to bind $\mathrm{CheW}_{1}$ and $\mathrm{CheW}_{2}$. Unbound proteins were washed away. Bound proteins were collected and separated on the $12 \%(\mathrm{wt} / \mathrm{vol})$ sodium dodecyl sulfate polyacrylamide gel electrophoresis. $\mathrm{CheW}_{1}$ and $\mathrm{CheW}_{2}$ were detected by Western blot. A SalT-His fusion protein, which is unrelated to the chemotaxis, was used as a negative control and was conducted in the pull-down assay in parallel. Lane 1, the eluate from the resins containing CheA-His; lane 2, the eluate from the resins containing SalT-His as the negative control; lane 3, the crude extract of C58 $\Delta a$ as the positive control. were grown in lysogeny broth liquid or agar medium at $37^{\circ} \mathrm{C}$ (Sambrook et al. 1989). A. tumefaciens strains were grown in $\mathrm{MG} / \mathrm{L}$ or $\mathrm{AB}$-sucrose liquid or agar medium at $28^{\circ} \mathrm{C}$ (Cangelosi et al. 1991; Gelvin 2006). Antibiotic concentrations were used for $E$. coli at final concentrations of ampicillin at $100 \mu \mathrm{g} / \mathrm{ml}$ and kanamycin at $50 \mu \mathrm{g} / \mathrm{ml}$ and, for A. tumefaciens, kanamycin at $100 \mu \mathrm{g} / \mathrm{ml}$ and carbenicillin at $100 \mu \mathrm{g} / \mathrm{ml}$.

\section{DNA manipulations.}

DNA manipulations followed the standard molecular protocols (Sambrook et al. 1989). A. tumefaciens DNA was prepared according to Charles and Nester (1993). Plasmid DNA was purified with TIANprep Mini Plasmids Kit (Tiangen Biotech Corporation). Primer information is listed in Supplementary Table S2. PCR products and DNA fragments were purified from agarose gels using TaKaRa MiniBEST Agrose Gel DNA Extraction Kit (ver. 4.0; TaKaRa Corporation). E. coli competent cells were prepared according to the Inoue protocol and DNA was transferred into $E$. coli competent cells by heatshock (Sambrook et al. 1989). Plasmids were introduced into A. tumefaciens by electroporation (Cangelosi et al. 1991).

\section{Construction of deletion or substitution mutants of A. tumefaciens.}

The precise deletion or substitution of $A$. tumefaciens gene $c h e W_{1}$, che $W_{2}$, or $c h e A$ was constructed by the gene replacement procedure, as described previously (Guo et al. 2007a, $2009 \mathrm{~b}$ ). All of the plasmids that were used for these gene replacements were derived from the plasmid pEX $18 \mathrm{Km}$, which carried a kanamycin-resistant gene as the positive selection marker and a suicide gene $(s a c \mathrm{~B})$ as the counterselectable marker. All A. tumefaciens mutants generated by this gene replacement system were verified by PCR and DNA sequencing.

\section{Complementation construction of cheW or cheA mutants.}

The complementation of the cheW or cheA mutants was implemented by the introduction of plasmids that carried the

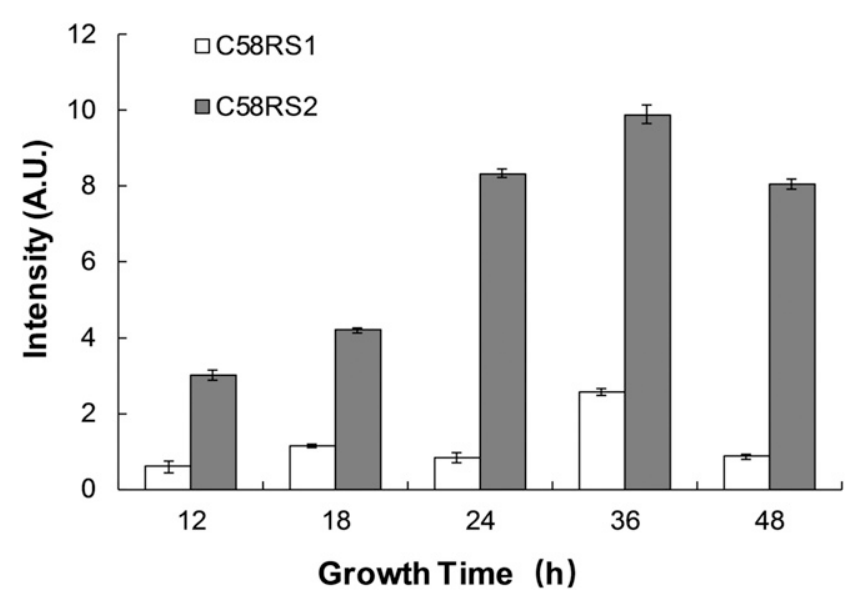

Fig. 7. Promoter activity analysis of two cheW homologs. The open reading frames of two cheW genes in Agrobacterium tumefaciens strain C58 were in situ substituted by a red fluorescent protein $(r f p)$ gene open reading frame, so that $r f p$ gene could be used as a reporter gene to detect the activities of the two cheW promoters in situ. Two A. tumefaciens strains, C58RS1 (che $W_{1}$ was substituted for $r f p$ ) and C58RS2 (cheW $W_{2}$ was substituted for $r f p$ ), were grown for the indicated time. Cells were collected in the indicated growth time. Cell crude extracts were used for the determination of fluorescence intensity. Fluorescence intensity data were normalized with the crude extract from wild-type cells to eliminate the interference of background fluorescence signals. Each experiment was performed at least in triplicate. 
cheW or cheA expression cassettes. To construct two cheW expression plasmids, DNA fragments of two wild-type cheW genes with their native promoters (approximately $500 \mathrm{bp}$ upstream of the start code) were amplified by PCR from C58 genomic DNA and inserted into plasmid pCB301. Thus, two che $W$ expression cassettes were promoted by their native promoters. To construct cheA expression plasmid, only the cheA coding sequence was amplified and inserted downstream of the lacZ promoter of the plasmid pUCA-19 so that the cheA expression cassette could be promoted by the lac $Z$ promoter. PrimeSTAR Max DNA polymerase for PCR was purchased from TaKaRa Corporation. Plasmids carrying the corresponding cheW or cheA expression cassettes were verified by restriction enzyme digestion and sequencing prior to electroporation into the corresponding mutants.

\section{Chemotaxis assays.}

Chemotactic responses to nutrient substances were assayed in $\mathrm{AB}$-sucrose medium containing $0.2 \%$ Bacto agar (Sangon Biotech Co., Inc.). Briefly, cell cultures in the middle-logarithmic growth phase were normalized to an optical density at $600 \mathrm{~nm}$ $\left(\mathrm{OD}_{600 \mathrm{~nm}}\right)$ of 0.5 . Equal amounts $(3 \mu \mathrm{l})$ of each strain were inoculated on the swim agar plate and incubated at $28^{\circ} \mathrm{C}$ for $48 \mathrm{~h}$ without disturbance for the incubation period. Radii of the colonies were measured and used to quantitate the chemotaxis toward nutrient substances (Sampedro et al. 2015).
Chemotactic responses to plant attractants were assayed as described by Su et al. (2006). Briefly, the fresh leaf disc (diameter $=5 \mathrm{~mm}$ ) of a Kalanchoe plant was placed at the center of the swim agar plate containing $0.2 \%$ Bacto agar. The strains were inoculated onto the plate $2.5 \mathrm{~cm}$ from the center of the leaf disc. Then, the plates were incubated at $28^{\circ} \mathrm{C}$ without disturbance and observed throughout a 48-h incubation period. Chemotactic response to AS was determined by the more sensitive capillary assay (Adler 1973; Shaw 1995). AS was purchased from Sangon Biotech Co., Inc.. The procedure of capillary assay was followed as described by Adler (1973), with minor modifications. Agrobacterial cells were harvested by centrifugation at 4,000 $\mathrm{rpm}$ for $3 \mathrm{~min}$ at room temperature $\left(25^{\circ} \mathrm{C}\right)$ and suspended in chemotaxis medium (EDTA at $0.1 \mathrm{mmol} /$ liter and $\mathrm{KH}_{2} \mathrm{PO}_{4}$ at $10 \mathrm{mmol} /$ liter, $\mathrm{pH}$ 7.0) to an $\mathrm{OD}_{600 \mathrm{~nm}}$ of 0.1. Agrobacterial suspension $(300 \mu \mathrm{l})$ was used to make a bacterial pond. The capillary tube was sealed at one end and filled with AS at $10^{-7} \mathrm{~mol} /$ liter dissolved in chemotaxis medium. The open end of the capillary tube was inserted into the bacterial pond and incubated for $1 \mathrm{~h}$ at room temperature; then, the solution in the capillary tube was expelled and completely transferred into $1 \mathrm{ml}$ of $\mathrm{AB}$-sucrose medium. Dilutions were plated in duplicate on $\mathrm{MG} / \mathrm{L}$ plates and incubated for 2 days at $28^{\circ} \mathrm{C}$. The colonies in the plate were counted and represented the number of the cells attracted to the capillary tube.
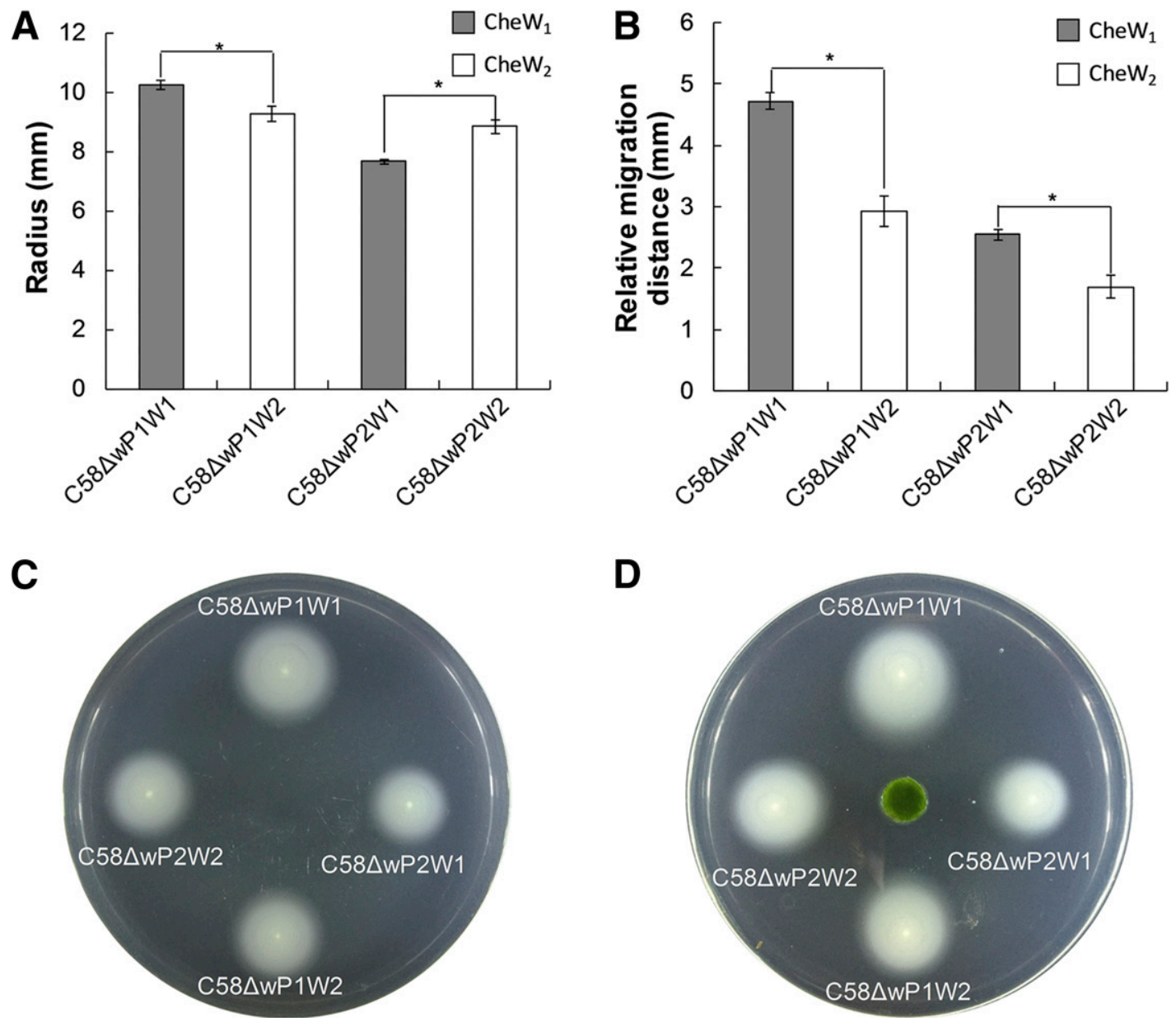

Fig. 8. Effects of two cheW open reading frames (ORF) under the control of identical promoters on chemotaxis. Four plasmids carrying different cheW expression cassettes were introduced into strain C58 $w$ to generate four Agrobacterium tumefaciens strains: C58 $\Delta w \mathrm{P} 1 \mathrm{~W} 1$ (che $W_{1}$ ORF controlled by its own

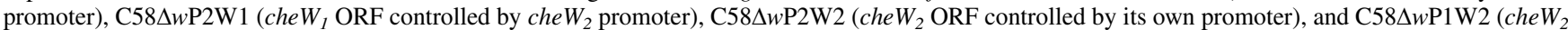
ORF controlled by che $W_{1}$ promoter). Chemotactic responses of these four $A$. tumefaciens strains to $\mathbf{A}$ and $\mathbf{C}$, nutrient substances and $\mathbf{B}$ and $\mathbf{D}$, plant attractants were tested. Each experiment was performed in triplicate. Asterisks $(*)$ represent $P$ value $<0.01$ between the two compared strains. 
Pull-down assay for detecting the interaction between CheA and CheW proteins.

E. coli BL21 (DE3) was utilized as the host to overproduce His-tagged CheA. Another His-tagged fusion protein, SalT-His, which is unrelated to the chemotaxis, was used as the negative control. The productions of His-tagged fusion proteins by E. coli followed the previous procedures (Gao et al. 2013; Yu et al. 2015). E. coli BL21 cells harboring the corresponding recombined pET-30a plasmids were grown to approximately $5 \times 10^{8} \mathrm{cell} / \mathrm{ml}$, and isopropylthio- $\beta$-D-galactoside was then added to the cultures at a final concentration of $0.3 \mathrm{mM}$ to induce the expression of the fusion proteins. After cultivation at $25^{\circ} \mathrm{C}$ for $4 \mathrm{~h}$, the cells were harvested by centrifugation $(6,000 \times g$, $\left.10 \mathrm{~min}, 4^{\circ} \mathrm{C}\right)$, washed twice with phosphate-buffered saline (PBS) buffer (10 mM, pH 7.4), and resuspended in a small volume of PBS buffer. All of the following procedures were carried out at $4^{\circ} \mathrm{C}$. The harvested cell suspension was sonicated to near clarity and the supernatant in the sonicated cell suspension was collected by centrifugation $(12,000 \times g$ for $30 \mathrm{~min})$. The supernatants from different samples were slowly added into $1.5 \mathrm{ml}$ of ProteinIos Ni-IDA Resins (Transgen Biotech) to allow the His-tagged fusion proteins to bind the resins. The fusion protein-bound resins were washed twice with PBS buffer (10 mM, pH 7.4), then incubated with $4 \mathrm{ml}$ of cell crude extract from $100 \mathrm{ml}$ of cell culture of the C58 $\Delta a$ strain, which was grown to $\mathrm{OD}_{600 \mathrm{~nm}}=1$ in $\mathrm{MG} / \mathrm{L}$ liquid medium. After incubation overnight at $4^{\circ} \mathrm{C}$ with gentle shaking, the resins were washed with 10 resin volumes of PBS buffer containing different concentrations of imidazole $(10,30$, and $50 \mathrm{mM})$ in the order of concentration increase to wash out the nonspecifically bound proteins. Finally, the specifically bound proteins on the resins were eluted with $500 \mu \mathrm{l}$ of PBS buffer containing $250 \mathrm{mM}$ imidazole.

\section{Generation of polyclonal rabbit antibodies against $\mathrm{CheW}_{1}$ and $\mathrm{CheW}_{2}$.}

Polyclonal rabbit antibodies against two $\mathrm{CheW}$ proteins were provided by GenScript Corporation. To obtain the polyclonal antibodies that can discriminate the two $\mathrm{CheW}$ proteins, peptide fragments from the variable sequences of the two CheW proteins were artificially synthesized and used as the antigens to generate antibodies against the two CheW proteins in New Zealand rabbits. To test whether the polyclonal antibodies can discriminate between the two CheW proteins, E. coli BL21 (DE3) was used as the host to heterogeneously produce the individual CheW, so that it was impossible for two CheW proteins to coexist in one strain. The specificities of the antibodies against the two $\mathrm{CheW}$ proteins were verified by the heterogeneously produced individual CheW using Western blot.

\section{Electrophoresis and immunoblotting analyses.}

Electrophoresis and immunoblotting analyses were carried out as described before (Yang et al. 2015). For sodium dodecyl sulfate polyacrylamide gel electrophoresis (SDS-PAGE), the harvested bacterial cells from different samples were washed twice in PBS buffer (10 mM, pH 7.4) and resuspended to the same cell density. Equal amounts of cell suspensions from these different samples were mixed with $6 \times$ protein loading buffer and boiled for $6 \mathrm{~min}$. Equal volumes of the whole-cell lysates from different cell suspensions were loaded for SDSPAGE. For immunoblotting, proteins were electrophoretically transferred to $0.22-\mu \mathrm{m}$ pore size hydrophilic polyvinylidene difluoride membranes (Merck Millipore) and were detected with the BCIP/NBT alkaline phosphatase color development kit (Beyotime Biotechnology Corp.), according to the procedure provided by the manufacturer. Polyclonal antibodies against the variable sequence regions of two $\mathrm{CheW}$ proteins were used as the primary antibodies for detection.

\section{Confocal laser microscopy observation of agrobacterial cells.}

For microscopy observation, agrobacterial cells from midlogphase cultures were added onto the center of the slides. A coverslip was placed on top of the culture droplet. The edges of the coverslip were sealed with acrylic polymer to prevent drying. A. tumefaciens cells were visualized by a Leica TCS SP8 STED $3 \mathrm{X}$ system using an Ar laser (excitation wavelength of $488 \mathrm{~nm}$ and emission wavelength of 500 to $550 \mathrm{~nm}$ ) and a $\times 100$ oil immersion objective. The images were analyzed and edited using LAS X Core Offline, version 3.0.2.

\section{Determination of fluorescence intensity.}

A RFP, TurboRFP, was used as the reporter protein to report the activity of the $c h e W_{1}$ or che $W_{2}$ promoter. The red fluorescence intensity in the agrobacterial cell lysate supernatant was used to quantitate the expression level of the $r f p$ gene under the control of the che $W_{1}$ or che $W_{2}$ promoter. The procedure for the collection of cell lysate supernatant and the determination of fluorescence intensity is as follows. Agrobacterial cells were collected from the overnight cultures in MG/L liquid medium, washed twice with $\mathrm{AB}$-sucrose liquid medium, and then diluted to $\mathrm{OD}_{600 \mathrm{~nm}}=0.1$ with $\mathrm{AB}$-sucrose liquid medium. The cells were harvested after being cultured in $\mathrm{AB}$-sucrose liquid medium at $28^{\circ} \mathrm{C}$ for the indicated time. The harvested cells were washed twice with PBS buffer and sonicated to near clarity. The cell lysate supernatants from these cell samples cultured for different times were collected by centrifugation $(12,000 \times g$ for $30 \mathrm{~min}$ ) and adjusted to the same protein concentration. The red fluorescence intensities of these different supernatant samples were measured in triplicate using a Varian Cary Eclipse fluorescence spectrophotometer at an excitation wavelength of $553 \mathrm{~nm}$ and emission detection at $574 \mathrm{~nm}$. Whole-cell lysate supernatant of wild-type C58 was used to eliminate the interference of background fluorescence.

\section{ACKNOWLEDGMENTS}

We thank R. Song (College of Veterinary Medicine, Yangzhou University) for help with confocal laser-microscopy observation.

\section{LITERATURE CITED}

Abedrabbo, S., Castellon, J., Collins, K. D., Johnson, K. S., and Ottemann, K. M. 2017. Cooperation of two distinct coupling proteins creates chemosensory network connections. Proc. Natl. Acad. Sci. U.S.A. 114: 2970-2975.

Adadevoh, J. S., Triolo, S., Ramsburg, C. A., and Ford, R. M. 2016. Chemotaxis increases the residence time of bacteria in granular media containing distributed contaminant sources. Environ. Sci. Technol. 50: $181-187$.

Adler, J. 1973. A method for measuring chemotaxis and use of the method to determine optimum conditions for chemotaxis by Escherichia coli. J. Gen. Microbiol. 74:77-91.

Alexander, R. P., Lowenthal, A. C., Harshey, R. M., and Ottemann, K. M. 2010. CheV: CheW-like coupling proteins at the core of the chemotaxis signaling network. Trends Microbiol. 18:494-503.

Alexandre, G. 2015. Chemotaxis control of transient cell aggregation. J. Bacteriol. 197:3230-3237.

Alexandre, G., and Zhulin, I. B. 2003. Different evolutionary constraints on chemotaxis proteins $\mathrm{CheW}$ and $\mathrm{CheY}$ revealed by heterologous expression studies and protein sequence analysis. J. Bacteriol. 185: 544-552.

Ashby, A. M., Watson, M. D., Loake, G. J., and Shaw, C. H. 1988. Ti plasmid-specified chemotaxis of Agrobacterium tumefaciens C58 $\mathrm{C}^{1}$ toward vir-inducing phenolic compounds and soluble factors from monocotyledonous and dicotyledonous plants. J. Bacteriol. 170: 4181-4187 
Ashby, A. M., Watson, M. D., and Shaw, C. H. 1987. A Ti-plasmid determined function is responsible for chemotaxis of Agrobacterium tumefaciens towards the plant wound product acetosyringone. FEMS Microbiol. Lett. 41:189-192.

Bi, S., and Lai, L. 2015. Bacterial chemoreceptors and chemoeffectors. Cell. Mol. Life Sci. 72:691-708.

Boukhvalova, M., VanBruggen, R., and Stewart, R. C. 2002a. CheA kinase and chemoreceptor interaction surfaces on CheW. J. Biol. Chem. 277: 23596-23603.

Boukhvalova, M. S., Dahlquist, F. W., and Stewart, R. C. 2002b. CheW binding interactions with CheA and Tar. Importance for chemotaxis signaling in Escherichia coli. J. Biol. Chem. 277:22251-22259.

Bourras, S., Rouxel, T., and Meyer, M. 2015. Agrobacterium tumefaciens gene transfer: How a plant pathogen hacks the nuclei of plant and nonplant organisms. Phytopathology 105:1288-1301.

Briegel, A., and Jensen, G. 2017. Progress and potential of electron cryotomography as illustrated by its application to bacterial chemoreceptor arrays. Annu. Rev. Biophys. 46:1-21.

Browning, D. F., and Busby, S. J. 2016. Local and global regulation of transcription initiation in bacteria. Nat. Rev. Microbiol. 14:638-650.

Butler, S. M., Nelson, E. J., Chowdhury, N., Faruque, S. M., Calderwood, S. B., and Camilli, A. 2006. Cholera stool bacteria repress chemotaxis to increase infectivity. Mol. Microbiol. 60:417-426.

Cangelosi, G. A., Best, E. A., Martinetti, G., and Nester, E. W. 1991 Genetic analysis of Agrobacterium. Methods Enzymol. 204:384-397.

Cardozo, M. J., Massazza, D. A., Parkinson, J. S., and Studdert, C. A. 2010. Disruption of chemoreceptor signalling arrays by high levels of CheW, the receptor-kinase coupling protein. Mol. Microbiol. 75:1171-1181.

Chandran, V. 2013. Type IV secretion machinery: Molecular architecture and function. Biochem. Soc. Trans. 41:17-28.

Charles, T. C., and Nester, E. W. 1993. A chromosomally encoded twocomponent sensory transduction system is required for virulence of Agrobacterium tumefaciens. J. Bacteriol. 175:6614-6625.

Dogra, G., Purschke, F. G., Wagner, V., Haslbeck, M., Kriehuber, T., Hughes, J. G., Van Tassell, M. L., Gilbert, C., Niemeyer, M., Ray, W. K., Helm, R. F., and Scharf, B. E. 2012. Sinorhizobium meliloti CheA complexed with CheS exhibits enhanced binding to CheY1, resulting in accelerated CheY1 dephosphorylation. J. Bacteriol. 194:1075-1087.

Erhardt, M. 2016. Strategies to block bacterial pathogenesis by interference with motility and chemotaxis. Curr. Top. Microbiol. Immunol. 398: 185-205.

Escobar, M. A., and Dandekar, A. M. 2003. Agrobacterium tumefaciens as an agent of disease. Trends Plant Sci. 8:380-386.

Falke, J. J., and Piasta, K. N. 2014. Architecture and signal transduction mechanism of the bacterial chemosensory array: Progress, controversies, and challenges. Curr. Opin. Struct. Biol. 29:85-94.

Gao, D., Bian, X., Guo, M., Wang, J., and Zhang, X. 2013. Identification and characterization of the biochemical function of Agrobacterium T-complex-recruiting protein Atu5117. FEBS J. 280:4865-4875.

Gelvin, S. B. 2006. Agrobacterium virulence gene induction. Methods Mol. Biol. 343:77-84.

Goodner, B., Hinkle, G., Gattung, S., Miller, N., Blanchard, M., Qurollo, B., Goldman, B. S., Cao, Y., Askenazi, M., Halling, C., Mullin, L., Houmiel, K., Gordon, J., Vaudin, M., Iartchouk, O., Epp, A., Liu, F., Wollam, C., Allinger, M., Doughty, D., Scott, C., Lappas, C., Markelz, B., Flanagan, C., Crowell, C., Gurson, J., Lomo, C., Sear, C., Strub, G., Cielo, C., and Slater, S. 2001. Genome sequence of the plant pathogen and biotechnology agent Agrobacterium tumefaciens C58. Science 294: 2323-2328.

Griswold, I. J., and Dahlquist, F. W. 2002. The dynamic behavior of CheW from Thermotoga maritima in solution, as determined by nuclear magnetic resonance: Implications for potential protein-protein interaction sites. Biophys. Chem. 101-102:359-373.

Guo, M., Bian, X., Wu, X., and Wu, M. 2011. Agrobacterium-mediated genetic transformation: History and progress. Pages 3-28 in: Genetic Transformation. M. Alvarez, ed. InTech, Rijeka, Croatia.

Guo, M., Gao, D., and Jin, Y. 2009a. Progress in the formation and transfer of Agrobacterium T-complex. Prog. Biochem. Biophys. 36:1408-1414.

Guo, M., Hou, Q., Hew, C. L., and Pan, S. Q. 2007a. Agrobacterium VirD2binding protein is involved in tumorigenesis and redundantly encoded in conjugative transfer gene clusters. Mol. Plant-Microbe Interact. 20: 1201-1212.

Guo, M., Huang, Z., and Yang, J. 2017. Is there any crosstalk between the chemotaxis and virulence induction signaling in Agrobacterium tumefaciens? Biotechnol. Adv. 35:505-511.

Guo, M., Jin, S., Sun, D., Hew, C. L., and Pan, S. Q. 2007b. Recruitment of conjugative DNA transfer substrate to Agrobacterium type IV secretion apparatus. Proc. Natl. Acad. Sci. U.S.A. 104:20019-20024.
Guo, M., Zhu, Q., and Gao, D. 2009b. Development and optimization of method for generating unmarked A. tumefaciens mutants. Prog. Biochem. Biophys. 36:556-565.

Harighi, B. 2008. Role of CheY1 and CheY2 in the chemotaxis of A. tumefaciens toward acetosyringone. Curr. Microbiol. 56:547-552.

Harighi, B. 2009. Genetic evidence for CheB- and CheR-dependent chemotaxis system in A. tumefaciens toward acetosyringone. Microbiol. Res. 164:634-641.

Hawes, M. C., and Smith, L. Y. 1989. Requirement for chemotaxis in pathogenicity of Agrobacterium tumefaciens on roots of soil-grown pea plants. J. Bacteriol. 171:5668-5671.

Hawes, M. C., Smith, L. Y., and Howarth, A. J. 1988. Agrobacterium tumefaciens mutants deficient in chemotaxis to root exudates. Mol. Plant-Microbe Interact. 1:182-186.

He, K., and Bauer, C. E. 2014. Chemosensory signaling systems that control bacterial survival. Trends Microbiol. 22:389-398.

Hess, J. F., Oosawa, K., Kaplan, N., and Simon, M. I. 1988. Phosphorylation of three proteins in the signaling pathway of bacterial chemotaxis. Cell 53: 79-87.

Jones, C. W., and Armitage, J. P. 2015. Positioning of bacterial chemoreceptors. Trends Microbiol. 23:247-256.

Kim, H., and Farrand, S. K. 1998. Opine catabolic loci from Agrobacterium plasmids confer chemotaxis to their cognate substrates. Mol. PlantMicrobe Interact. 11:131-143.

Krell, T., Lacal, J., Reyes-Darias, J. A., Jimenez-Sanchez, C., Sungthong, R., and Ortega-Calvo, J. J. 2013. Bioavailability of pollutants and chemotaxis. Curr. Opin. Biotechnol. 24:451-456.

Kudryasheva, N. S., and Tarasova, A. S. 2015. Pollutant toxicity and detoxification by humic substances: Mechanisms and quantitative assessment via luminescent biomonitoring. Environ. Sci. Pollut. Res. Int. 22:155-167.

Lang, J., and Faure, D. 2014. Functions and regulation of quorum-sensing in Agrobacterium tumefaciens. Front. Plant Sci. 5:14.

Li, Y., Hu, Y., Fu, W., Xia, B., and Jin, C. 2007. Solution structure of the bacterial chemotaxis adaptor protein $\mathrm{CheW}$ from Escherichia coli Biochem. Biophys. Res. Commun. 360:863-867.

Li, Z.-H., Dong, K., Sun, J.-C., Yuan, J.-P., Hu, B.-Y., Liu, J.-X., Zhao, G.-P., and Guo, X.-K. 2006. Characterization of cheW genes of Leptospira interrogans and their effects in Escherichia coli. Acta Biochim. Biophys. Sin. (Shanghai) 38:79-88.

Liu, J. D., and Parkinson, J. S. 1989. Role of CheW protein in coupling membrane receptors to the intracellular signaling system of bacterial chemotaxis. Proc. Natl. Acad. Sci. U.S.A. 86:8703-8707.

Liu, J. D., and Parkinson, J. S. 1991. Genetic evidence for interaction between the CheW and Tsr proteins during chemoreceptor signaling by Escherichia coli. J. Bacteriol. 173:4941-4951.

Loake, G. J., Ashby, A. M., and Shaw, C. H. 1988. Attraction of Agrobacterium tumefaciens $\mathrm{C}_{58 \mathrm{C}^{1}}$ towards sugars involves a highly sensitive chemotaxis system. Microbiology 134:1427-1432.

Low, H. H., Gubellini, F., Rivera-Calzada, A., Braun, N., Connery, S., Dujeancourt, A., Lu, F., Redzej, A., Fronzes, R., Orlova, E. V., and Waksman, G. 2014. Structure of a type IV secretion system. Nature 508: 550-553.

Lowenthal, A. C., Simon, C., Fair, A. S., Mehmood, K., Terry, K., Anastasia, S., and Ottemann, K. M. 2009. A fixed-time diffusion analysis method determines that the three cheV genes of Helicobacter pylori differentially affect motility. Microbiology 155:1181-1191.

Mangwani, N., Kumari, S., and Das, S. 2016. Bacterial biofilms and quorum sensing: Fidelity in bioremediation technology. Biotechnol. Genet. Eng. Rev. 32:43-73.

Martin, A. C., Wadhams, G. H., and Armitage, J. P. 2001. The roles of the multiple CheW and CheA homologues in chemotaxis and in chemoreceptor localization in Rhodobacter sphaeroides. Mol. Microbiol. 40:1261-1272.

Matveeva, T. V., and Lutova, L. A. 2014. Horizontal gene transfer from Agrobacterium to plants. Front. Plant Sci. 5:326.

McCullen, C. A., and Binns, A. N. 2006. Agrobacterium tumefaciens and plant cell interactions and activities required for interkingdom macromolecular transfer. Annu. Rev. Cell Dev. Biol. 22:101-127.

Merritt, P. M., Danhorn, T., and Fuqua, C. 2007. Motility and chemotaxis in Agrobacterium tumefaciens surface attachment and biofilm formation. J. Bacteriol. 189:8005-8014.

Minchin, S. D., and Busby, S. J. 2009. Analysis of mechanisms of activation and repression at bacterial promoters. Methods 47:6-12.

Montaño, M., Gutleb, A. C., and Murk, A. J. 2013. Persistent toxic burdens of halogenated phenolic compounds in humans and wildlife. Environ. Sci. Technol. 47:6071-6081.

Nester, E. W. 2015. Agrobacterium: Nature's genetic engineer. Front. Plant Sci. 5:730. 
Nishiyama, S., Garzón, A., and Parkinson, J. S. 2014. Mutational analysis of the P1 phosphorylation domain in Escherichia coli CheA, the signaling kinase for chemotaxis. J. Bacteriol. 196:257-264.

Ortega, D. R., and Zhulin, I. B. 2016. Evolutionary genomics suggests that CheV is an additional adaptor for accommodating specific chemoreceptors within the chemotaxis signaling complex. PLOS Comput. Biol. 12:e1004723.

Parke, D., Ornston, L. N., and Nester, E. W. 1987. Chemotaxis to plant phenolic inducers of virulence genes is constitutively expressed in the absence of the Ti plasmid in Agrobacterium tumefaciens. J. Bacteriol. 169:5336-5338.

Parkinson, J. S., Hazelbauer, G. L., and Falke, J. J. 2015. Signaling and sensory adaptation in Escherichia coli chemoreceptors: 2015 Update. Trends Microbiol. 23:257-266.

Parkinson, J. S., and Houts, S. E. 1982. Isolation and behavior of Escherichia coli deletion mutants lacking chemotaxis functions. J. Bacteriol. 151: 106-113.

Piñas, G. E., Frank, V., Vaknin, A., and Parkinson, J. S. 2016. The source of high signal cooperativity in bacterial chemosensory arrays. Proc. Natl. Acad. Sci. U.S.A. 113:3335-3340.

Pittman, M. S., Goodwin, M., and Kelly, D. J. 2001. Chemotaxis in the human gastric pathogen Helicobacter pylori: Different roles for CheW and the three $\mathrm{CheV}$ paralogues, and evidence for CheV2 phosphorylation. Microbiology 147:2493-2504.

Pitzschke, A. 2013. Agrobacterium infection and plant defense-transformation success hangs by a thread. Front. Plant Sci. 4:519.

Porter, S. L., Wadhams, G. H., and Armitage, J. P. 2011. Signal processing in complex chemotaxis pathways. Nat. Rev. Microbiol. 9:153-165.

Rosario, M. M., Fredrick, K. L., Ordal, G. W., and Helmann, J. D. 1994. Chemotaxis in Bacillus subtilis requires either of two functionally redundant CheW homologs. J. Bacteriol. 176:2736-2739.

Salah Ud-Din, A. I. M., and Roujeinikova, A. 2017. Methyl-accepting chemotaxis proteins: A core sensing element in prokaryotes and archaea. Cell. Mol. Life. Sci. 74:3293-3303.

Sambrook, J. F., Fritsch, E. F., and Maniatis, T. 1989. Molecular Cloning: A Laboratory Manual, 2nd ed. Cold Spring Harbor Laboratory Press, Cold Spring Harbor, NY.

Sampedro, I., Parales, R. E., Krell, T., and Hill, J. E. 2015. Pseudomonas chemotaxis. FEMS Microbiol. Rev. 39:17-46.

Scharf, B. E., Hynes, M. F., and Alexandre, G. M. 2016. Chemotaxis signaling systems in model beneficial plant-bacteria associations. Plant Mol. Biol. 90:549-559.

Shaw, C. H. 1995. Agrobacterium tumefaciens chemotaxis protocols. Methods Mol. Biol. 44:29-36.

Sourjik, V., and Berg, H. C. 2000. Localization of components of the chemotaxis machinery of Escherichia coli using fluorescent protein fusions. Mol. Microbiol. 37:740-751.
Sourjik, V., and Wingreen, N. S. 2012. Responding to chemical gradients: Bacterial chemotaxis. Curr. Opin. Cell Biol. 24:262-268.

Springer, M. S., Goy, M. F., and Adler, J. 1977. Sensory transduction in Escherichia coli: Two complementary pathways of information processing that involve methylated proteins. Proc. Natl. Acad. Sci. U.S.A. 74 3312-3316.

Stachel, S. E., Messens, E., Van Montagu, M., and Zambryski, P. 1985. Identification of the signal molecules produced by wounded plant cells that activate T-DNA transfer in Agrobacterium tumefaciens. Nature 318: 624-629.

Su, S., Stephens, B. B., Alexandre, G., and Farrand, S. K. 2006. Lon protease of the $\alpha$-proteobacterium Agrobacterium tumefaciens is required for normal growth, cellular morphology and full virulence. Microbiology 152:1197-1207.

Subramoni, S., Nathoo, N., Klimov, E., and Yuan, Z. C. 2014. Agrobacterium tumefaciens responses to plant-derived signaling molecules. Front. Plant Sci. 5:322.

Wood, D. W., Setubal, J. C., Kaul, R., Monks, D. E., Kitajima, J. P., Okura, V. K., Zhou, Y., Chen, L., Wood, G. E., Almeida, N. F., Jr., Woo, L., Chen, Y., Paulsen, I. T., Eisen, J. A., Karp, P. D., Bovee, D., Sr., Chapman, P., Clendenning, J., Deatherage, G., Gillet, W., Grant, C., Kutyavin, T., Levy, R., Li, M. J., McClelland, E., Palmieri, A., Raymond, C., Rouse, G., Saenphimmachak, C., Wu, Z., Romero, P., Gordon, D., Zhang, S., Yoo, H., Tao, Y., Biddle, P., Jung, M., Krespan, W., Perry, M., Gordon-Kamm, B., Liao, L., Kim, S., Hendrick, C., Zhao, Z. Y., Dolan, M., Chumley, F., Tingey, S. V., Tomb, J. F., Gordon, M. P., Olson, M. V., and Nester, E. W. 2001. The genome of the natural genetic engineer Agrobacterium tumefaciens C58. Science 294:2317-2323.

Wright, E. L., Deakin, W. J., and Shaw, C. H. 1998. A chemotaxis cluster from Agrobacterium tumefaciens. Gene 220:83-89.

Yang, J., Wu, M., Zhang, X., Guo, M., and Huang, Z. 2015. Expression of Agrobacterium homolog genes encoding T-complex recruiting protein under virulence induction conditions. Front. Microbiol. 6:1379.

Yu, M., Zuo, J., Gu, H., Guo, M., and Yin, Y. 2015. Domain function dissection and catalytic properties of Listeria monocytogenes p60 protein with bacteriolytic activity. Appl. Microbiol. Biotechnol. 99: 10527-10537.

Zhang, K., Liu, J., Tu, Y., Xu, H., Charon, N. W., and Li, C. 2012. Two CheW coupling proteins are essential in a chemosensory pathway of Borrelia burgdorferi. Mol. Microbiol. 85:782-794.

Zhao, J., and Parkinson, J. S. 2006a. Cysteine-scanning analysis of the chemoreceptor-coupling domain of the Escherichia coli chemotaxis signaling kinase CheA. J. Bacteriol. 188:4321-4330.

Zhao, J., and Parkinson, J. S. 2006b. Mutational analysis of the chemoreceptorcoupling domain of the Escherichia coli chemotaxis signaling kinase CheA. J. Bacteriol. 188:3299-3307. 